\title{
Effects of Intercropping on Zinc Uptake of Maize and Sweet Potato Seedlings
}

\author{
Xingyu Zhang ${ }^{1, a}$, Li Wang ${ }^{2, b}$, Xingchao Zhang ${ }^{1, c}$, Caifang Wu ${ }^{1, d}$, and Lijin Lin $^{3, e^{*}}$ \\ ${ }^{1}$ College of Horticulture, Sichuan Agricultural University, Chengdu, China \\ ${ }^{2}$ College of Animal Science and Technology, Sichuan Agricultural University, Chengdu, China \\ ${ }^{3}$ Institute of Pomology and Olericulture, Sichuan Agricultural University, Chengdu, China \\ a1640792129@qq.com, ${ }^{b} 510830161 @ q q . c o m,{ }^{c}$ 1690508180@qq.com, d1843027126@qq.com, \\ ellj800924@163.com (Corresponding author) \\ Xingyu Zhang and Li Wang contributed equally to this work.
}

\section{Keywords: Intercropping; Zinc; Maize; Sweet potato}

Abstract. A pot experiment was carried out to study the effects of intercropping on zinc (Zn) uptake of maize and sweet potato seedlings. Intercropping with sweet potato increased the root biomass of maize seedlings, but reduced the stem, leaf and shoot biomasses of maize seedlings. Intercropping with maize increased the root, stem, leaf and shoot biomasses of sweet potato seedlings. Intercropping decreased the chlorophyll and carotenoid contents in maize seedlings, but increased that in sweet potato seedlings. Intercropping decreased $\mathrm{Zn}$ content in roots of maize seedlings, and increased $\mathrm{Zn}$ contents in stems, leaves and shoots of maize seedlings, which increased by $7.32 \%$ of shoots compared with the monoculture. For sweet potato, Intercropping increased $\mathrm{Zn}$ contents in roots, stems, leaves and shoots of maize seedlings, which increased by $30.76 \%$ of shoots compared with the monoculture. Therefore, intercropping could inhibit the growth of maize seedlings and promote the growth of sweet potato seedlings, and improve Zn uptake of two crops.

\section{Introduction}

The zinc $(\mathrm{Zn})$ is a necessary trace nutrient, and plays an important role in growth and development of crops [1]. In recent years, because the application of the increase fertilizer, the decrease of organic manure, high-yield varieties and the increase of cropping index, the farmland is lack of trace elements, especially the $\mathrm{Zn}$ deficiency [2]. At present, the $\mathrm{Zn}$ fertilizer is the most commonly used measures of $\mathrm{Zn}$ deficiency, but when mixed with the phosphorus or alkaline fertilizer, $\mathrm{Zn}$ can produce the chelation or insoluble solid compounds, so the Zn fertilizer can not mix with phosphate and alkaline fertilizers [3], which limit the role of the $\mathrm{Zn}$ fertilizer playing. Intercropping is an effective measure to improve the absorption efficiency of trace elements in crops, and also can make full use of soil and water resources [4]. Intercropping with other crops can significantly increase the yield and quality of maize compared with the monoculture, such as intercropping with soybean [5], wheat [6], bean [7] and pepper [8].

The maize and sweet potato are common crops, which are often intercropped with each other. When maize is intercropped with sweet potato, the Zn uptakes of two crops could be changed, but there are few studies about this. In this study, the seedlings of maize and sweet potato were planted together to study whether the intercropping could promote the growth of maize and sweet potato, and improve Zn uptake of two crops.

\section{Materials and Methods}

Materials. The soil samples used in this experiment were inceptisol soil, which were collected from the Ya'an campus farm of Sichuan Agricultural University $\left(29^{\circ} 59^{\prime} \mathrm{N}, 102^{\circ} 59^{\prime} \mathrm{E}\right)$ in May 2014. The basic properties of the soil are described in the reference of Lin et al. (2014) [9]. The total Zn content was $45.75 \mathrm{mg} / \mathrm{kg}$, and the exchangeable $\mathrm{Zn}$ content was $37.58 \mathrm{mg} / \mathrm{kg}$. 
Experimental Design. The soil samples were air-dried and passed through a 5-mm sieve. Three kilograms of the air-dried soil was weighed into each polyethylene pot $(15 \mathrm{~cm}$ high, $18 \mathrm{~cm}$ in diameter). In May 2014, the seeds of maize were directly sown into each pot with six seeds. When the maize seedlings emerged, planted the cutting of the sweet potato seedlings $(10 \mathrm{~cm}$ in length). The monoculture of each crop was kept four seedlings in each pot, and two seedlings of each crop for intercropping in each pot. The each treatment had six replicates. Daily watering to keep the soil moisture in the basin is about $80 \%$, and timely removal of other weeds, pests and diseases.

When two crop seedlings grow one month (Jun 2014), the upper mature leaves of two crop seedlings were collected to determine the photosynthetic pigment (chlorophyll $a$, chlorophyll $b$ and total chlorophyll) contents [10]. Then, the whole plants were gently removed. The roots and shoots were washed with tap water followed by deionized water, and the biomasses of root, stem and leaf were measured. After that, the roots, stems and leaves of two crops were dried at $80{ }^{\circ} \mathrm{C}$ to constant weight. The plant samples were finely ground and sieved through a $0.149 \mathrm{~mm}$ mesh nylon sieve for digesting, and the $\mathrm{Zn}$ concentrations were determined using an iCAP 6300 ICP spectrometer (Thermo Scientific, Waltham, MA, USA) [11]. The pot soils were air-dried and ground into powder (granule diameter, $1 \mathrm{~mm}$ ) to determine the soil $\mathrm{pH}$ and exchangeable $\mathrm{Zn}$ concentration. Soil $\mathrm{pH}$ was measured in a 1:2.5 (w/v) suspension of soil and deionized water, and the exchangeable $\mathrm{Zn}$ in the soil was extracted with DTPA-TEA and analyzed with an iCAP 6300 ICP spectrometer [11].

Statistical Analyses. Statistical analyses were conducted using SPSS 13.0 statistical software (IBM, Chicago, IL, USA). Data were analyzed by one-way analysis of variance with Duncan's multiple range test $(\mathrm{p}=0.05$ confidence level).

\section{Results and Discussion}

Biomass of Two Crops. Intercropping with sweet potato seedlings increased the root biomass of maize seedlings by $8.59 \%(p>0.05)$ compared with the monoculture, but reduced stem, leaf and shoot biomasses of maize seedlings by $25.80 \%(p<0.05), 8.49 \%(p<0.05)$ and $13.93 \%(p<0.05)$ respectively, compared with the monoculture (Table 1). These results indicating that intercropping with sweet potato seedlings could inhibit the growth of maize seedlings, which could be related to high biomass of sweet potato seedlings when planting. For sweet potato, when intercropping with maize seedlings, the root, stem, leaf and shoot biomasses of sweet potato seedlings increased compared with the monoculture, which increased by $10.44 \%(p<0.05), 9.38 \%(p>0.05), 35.67 \%(p$ $<0.05)$ and $29.68 \%(p<0.05)$ respectively (Table 1$)$. So, intercropping with maize seedlings could promote the growth of sweet potato seedlings.

Table 1 The biomass of two crops

\begin{tabular}{|l|c|c|c|c|}
\hline \multicolumn{1}{|c|}{ Treatments } & $\begin{array}{c}\text { Roots } \\
\text { (g/plant) }\end{array}$ & $\begin{array}{c}\text { Stems } \\
\text { (g/plant) }\end{array}$ & $\begin{array}{c}\text { Leaves } \\
\text { (g/plant) }\end{array}$ & $\begin{array}{c}\text { Shoots } \\
\text { (g/plant) }\end{array}$ \\
\hline Maize (monoculture) & $1.013 \pm 0.067 \mathrm{a}$ & $1.213 \pm 0.037 \mathrm{a}$ & $2.650 \pm 0.075 \mathrm{a}$ & $3.863 \pm 0.112 \mathrm{a}$ \\
\hline Maize (intercropping) & $1.100 \pm 0.050 \mathrm{a}$ & $0.900 \pm 0.034 \mathrm{~b}$ & $2.425 \pm 0.074 \mathrm{~b}$ & $3.325 \pm 0.109 \mathrm{~b}$ \\
\hline & & & & \\
\hline sweet potato (monoculture) & $0.833 \pm 0.027 \mathrm{~b}$ & $0.640 \pm 0.043 \mathrm{a}$ & $2.167 \pm 0.033 \mathrm{~b}$ & $2.807 \pm 0.076 \mathrm{~b}$ \\
\hline Sweet potato (intercropping) & $0.920 \pm 0.040 \mathrm{a}$ & $0.700 \pm 0.021 \mathrm{a}$ & $2.940 \pm 0.140 \mathrm{a}$ & $3.640 \pm 0.119 \mathrm{a}$ \\
\hline
\end{tabular}

Values are means $( \pm$ SE) of six replicate pots. Different lowercase letters within a column indicate significant differences (one-way analysis of variance followed by Duncan's multiple range test; $p<$ $0.05)$.

Photosynthetic Pigment Contents of Two Crops. Intercropping with sweet potato seedlings decreased the contents of chlorophyll $a$, chlorophyll $b$ and total chlorophyll of maize seedlings compared with the monoculture, which reduced by $17.21 \%(p<0.05), 28.76 \%(p<0.05), 19.36 \%(p$ $<0.05)$ and $17.87 \%(p<0.05)$ respectively (Table 2$)$. However, intercropping with maize seedlings 
increased the contents of chlorophyll $a$, chlorophyll $b$ and total chlorophyll of maize seedlings by $1.95 \%(p>0.05), 0.31 \%(p>0.05), 1.65 \%(p>0.05)$ and $45.14 \%(p<0.05)$ respectively, compared with the monoculture (Table 2).

Table 2 The photosynthetic pigment content of two crops

\begin{tabular}{|l|c|c|c|c|}
\hline \multicolumn{1}{|c|}{ Treatments } & $\begin{array}{c}\text { Chlorophyll } a \\
(\mathrm{mg} / \mathrm{g})\end{array}$ & $\begin{array}{c}\text { Chlorophyll } b \\
(\mathrm{mg} / \mathrm{g})\end{array}$ & $\begin{array}{c}\text { Total chlorophyll } \\
(\mathrm{mg} / \mathrm{g})\end{array}$ & $\begin{array}{c}\text { Carotenoid } \\
(\mathrm{mg} / \mathrm{g})\end{array}$ \\
\hline Maize (monoculture) & $2.051 \pm 0.063 \mathrm{~b}$ & $0.459 \pm 0.092 \mathrm{a}$ & $2.510 \pm 0.155 \mathrm{a}$ & $0.717 \pm 0.057 \mathrm{a}$ \\
\hline Maize (intercropping) & $1.698 \pm 0.066 \mathrm{a}$ & $0.327 \pm 0.004 \mathrm{a}$ & $2.024 \pm 0.070 \mathrm{~b}$ & $0.589 \pm 0.019 \mathrm{~b}$ \\
\hline & & & & \\
\hline sweet potato (monoculture) & $1.438 \pm 0.016 \mathrm{a}$ & $0.319 \pm 0.005 \mathrm{a}$ & $1.757 \pm 0.011 \mathrm{a}$ & $0.494 \pm 0.008 \mathrm{~b}$ \\
\hline Sweet potato (intercropping) & $1.466 \pm 0.172 \mathrm{a}$ & $0.320 \pm 0.039 \mathrm{a}$ & $1.786 \pm 0.211 \mathrm{a}$ & $0.717 \pm 0.061 \mathrm{a}$ \\
\hline
\end{tabular}

Values are means $( \pm$ SE) of six replicate pots. Different lowercase letters within a column indicate significant differences (one-way analysis of variance followed by Duncan's multiple range test; $p<$ $0.05)$.

Zn Contents in Two Crops. Intercropping with sweet potato seedlings decreased Zn content in roots of maize seedlings, which decreased by $1.36 \%(p>0.05)$ compared with the monoculture (Table 3). Zn contents in stems, leaves and shoots of maize seedlings were increased by intercropping with sweet potato seedlings compared with the monoculture. Intercropping with sweet potato seedlings increased $\mathrm{Zn}$ contents in stems, leaves and shoots of maize seedlings by $12.12 \%(p<0.05), 4.32 \%(p$ $<0.05)$ and $7.32 \%(p<0.05)$ respectively, compared with the monoculture. For sweet potato, intercropping with maize seedlings increased $\mathrm{Zn}$ contents in roots, stems, leaves and shoots of sweet potato seedlings, which increased by $16.05 \%(p<0.05), 30.68 \%(p<0.05), 30.40 \%(p<0.05)$ and $30.76 \%(p<0.05)$ respectively, compared with the monoculture (Table 3). Therefore, Intercropping is benefit to $\mathrm{Zn}$ uptake of maize and sweet potato seedlings.

Table 3 The $\mathrm{Zn}$ content in two crops

\begin{tabular}{|l|c|c|c|c|}
\hline \multicolumn{1}{|c|}{ Treatments } & $\begin{array}{c}\text { Roots } \\
(\mathrm{mg} / \mathrm{kg})\end{array}$ & $\begin{array}{c}\text { Stems } \\
(\mathrm{mg} / \mathrm{kg})\end{array}$ & $\begin{array}{c}\text { Leaves } \\
(\mathrm{mg} / \mathrm{kg})\end{array}$ & $\begin{array}{c}\text { Shoots } \\
(\mathrm{mg} / \mathrm{kg})\end{array}$ \\
\hline Maize (monoculture) & $142.98 \pm 1.02 \mathrm{a}$ & $65.77 \pm 2.53 \mathrm{~b}$ & $89.36 \pm 2.86 \mathrm{~b}$ & $81.95 \pm 0.49 \mathrm{~b}$ \\
\hline Maize (intercropping) & $141.03 \pm 0.97 \mathrm{a}$ & $73.74 \pm 2.06 \mathrm{a}$ & $93.22 \pm 1.28 \mathrm{a}$ & $87.95 \pm 1.47 \mathrm{a}$ \\
\hline & & & & \\
\hline sweet potato (monoculture) & $103.42 \pm 1.58 \mathrm{~b}$ & $39.01 \pm 1.99 \mathrm{~b}$ & $41.87 \pm 1.13 \mathrm{~b}$ & $41.22 \pm 1.30 \mathrm{~b}$ \\
\hline Sweet potato (intercropping) & $120.02 \pm 1.98 \mathrm{a}$ & $50.98 \pm 1.02 \mathrm{a}$ & $54.60 \pm 1.40 \mathrm{a}$ & $53.90 \pm 1.28 \mathrm{a}$ \\
\hline
\end{tabular}

Values are means $( \pm \mathrm{SE})$ of six replicate pots. Different lowercase letters within a column indicate significant differences (one-way analysis of variance followed by Duncan's multiple range test; $p<$ $0.05)$.

Soil pH and Exchangeable Zn Concentration. When intercropping, the soil $\mathrm{pH}$ was between maize monoculture and sweet potato monoculture (Fig. 1). The order of soil $\mathrm{pH}$ was ranked as sweet potato monoculture > maize intercropping with sweet potato > maize monoculture. The soil exchangeable $\mathrm{Zn}$ concentration of intercropping was also between maize monoculture and sweet potato monoculture (Fig. 2). The order of soil exchangeable Zn concentration was ranked as sweet potato monoculture $>$ maize intercropping with sweet potato $>$ maize monoculture.

\section{Conclusions}

When maize seedlings intercropped with sweet potato seedlings, the shoot biomass of maize reduced, but the shoot biomass of sweet potato increased. Intercropping decreased the chlorophyll and 
carotenoid contents in maize seedlings, but increased that in sweet potato seedlings. Intercropping increased $\mathrm{Zn}$ uptake of maize and sweet potato seedlings. Therefore, intercropping could inhibit the growth of maize seedlings and promote the growth of sweet potato seedlings, and improve $\mathrm{Zn}$ uptake of two crops. Further research should focus on the root secretion of two crops when intercropping.

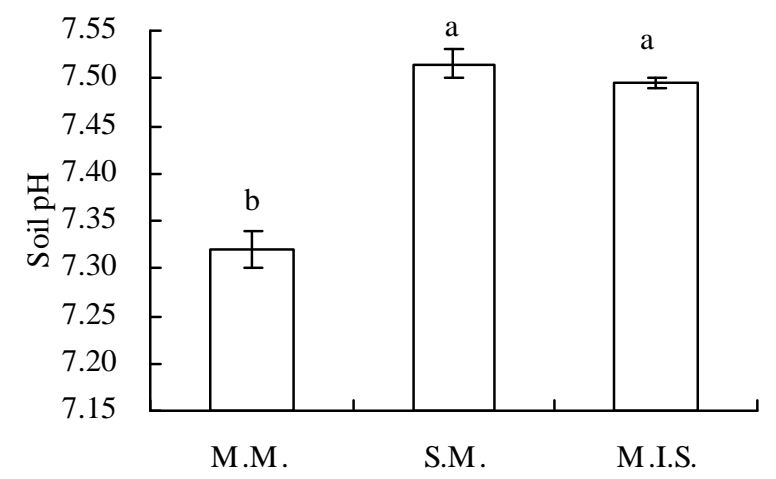

Fig. 1. Soil $\mathrm{pH}$ of maize intercropping with sweet potato. M.M. = maize monoculture, S.M. = sweet potato monoculture, M.I.S. = maize intercropping with sweet potato.

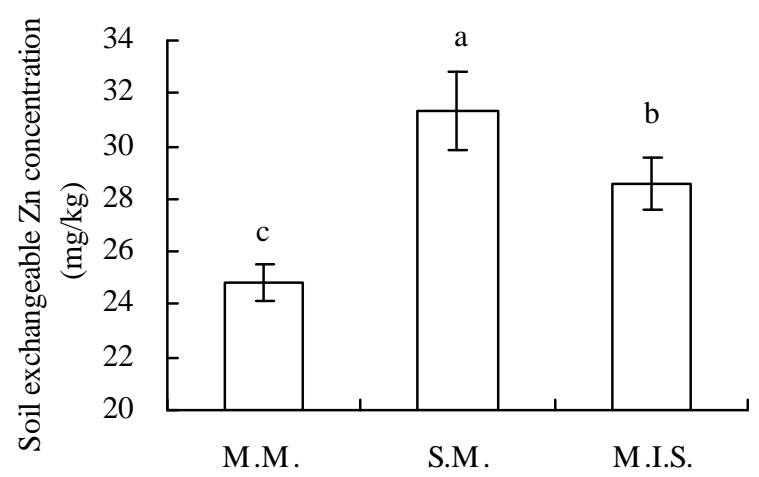

Fig. 2. Soil $\mathrm{Zn}$ concentration of maize intercropping with sweet potato. M.M. = maize monoculture, S.M. = sweet potato monoculture, M.I.S. = maize intercropping with sweet potato.

\section{Acknowledgements}

This work was financially supported by the Undergraduate Thesis Breeding Program of Sichuan Agricultural University (2015).

\section{References}

[1] H. Rehman, T. Aziz, M. Farooq, A. Wakeel and Z. Remgel: Plant and Soil Vol. 361 (2012), p. 203.

[2] C.Q. Zou and F.S. Zhang: Progress and Perspective of Micronutrients in Soil-Crop Systems (China Agricultural University press, Beijing 2009).

[3] X.L. Zhou: Heilongjiang Science and Technology Information Vol. 26 (2014), p. 263.

[4] H.Y. Xia, J.H. Zhao, J.H. Sun, Y.F. Xue, E. Tristan, X.G. Bao, F.S. Zhang and L. Li: Scientia Sinica Vitae Vol. 43 (2013), p. 557.

[5] M. Tsubo and S. Walker: Agricultural and Forest Meteorology Vol. 110 (2002), p. 203.

[6] L. Li, J.H. Sun, F.S. Zhang, X.L. Li, S.C. Yang and Z. Rengel: Field Crops Research Vol. 71 (2001), p. 123.

[7] L. Li, S. Yang, X. Li, F. Zhang and P. Christie: Plant and Soil Vol. 212 (1999), p. 105.

[8] Q. Xu, Z.H. Cheng, T. Lu and B.Y. Xie: Acta Botanica Boreali-Occidentalia Sinica Vol. 30 (2010), p. 350.

[9] L. Lin, J. Shi, Q. Liu, M. Liao and L. Mei: Environmental Monitoring and Assessment Vol. 186 (2014), p. 4051.

[10]Z.B. Hao, J. Cang and Z. Xu: Plant Physiology Experiment (Harbin Institute of Technology Press, Harbin, China 2004).

[11] S.D. Bao: Agrochemical Soil Analysis (3 ${ }^{\text {rd }}$ edition, China Agriculture Press, Beijing 2000). 